\title{
The prevalence of anti-Helicobacter (Campylobacter) pylori antibodies in patients and healthy blood donors
}

\author{
R. J. L. F. LOFFELD, E. STOBBERINGH*, J. P. VAN SPREEUWEL $\ddagger$, J. A. FLENDRIG \\ and J. W. ARENDSt
}

Departments of Internal Medicine, *Microbiology and †Pathology, University Hospital Maastricht, PO Box 1918, 6201 BX Maastricht, The Netherlands

\begin{abstract}
Summary. An enzyme linked immunosorbent assay (ELISA) with a sonicated suspension of Helicobacter (Campylobacter) pylori as antigen was used to detect anti$H$. pylori antibodies in 517 patients without dyspepsia or peptic ulcer symptoms and 401 healthy blood donors. The criterion of seropositivity was determined from a receiver operating curve computed with the values of optical densities of 48 sera from dyspeptic patients with proven helicobacter-associated gastritis and 16 sera from dyspeptic patients with proven helicobacter-associated gastritis and 16 sera from dyspeptic patients with normal antral mucosa and no microbiological or histological evidence of $H$.pylori infection. The $227(44 \%)$ seropositive persons amongst the patient group appeared to be significantly higher than the $142(35 \%)$ sera with antibodies in the blood donors tested $(\mathrm{p}<0.03)$, even when adjustment was made for increasing age. We conclude that the prevalence of antibodies against $H$.pylori increases with age and that although antibodies are more prevalent in patients attending a hospital than in healthy blood donors, seropositivity suggestive of current or past infection can be found in one third of a randomly chosen population of blood donors.
\end{abstract}

\section{Introduction}

Helicobacter (Campylobacter) pylori has been implicated as a common cause of chronic active gastritis and, possibly, peptic ulcer disease. ${ }^{1-5}$ Early debate as to whether $H$. pylori is an opportunist pathogen attracted to inflammed antral mucosa, or is implicated as the cause of type B (antral) gastritis, tends to be resolving in favour of the latter hypothesis. ${ }^{2}$ Earlier studies on the prevalence of gastritis have shown an increase with age. ${ }^{6-8}$ Since type B (antral) gastritis is almost always associated with $H$. pylori $^{1-5}$ an increasing prevalence of this micro-organism with age would be expected. However, because diagnosis of active $\boldsymbol{H}$.pylori infection has previously relied on invasive diagnostic procedures (endoscopy and biopsy), large scale population studies are sparse and no exact data are available on the presence of this infection in relation to age.

Patients infected with $H$. pylori develop a local as well as a systemic antibody response, ${ }^{9-11}$ and serological techniques can be used for the assess-

Received 12 June 1989; revised version accepted 23 Nov. 1989. $\ddagger$ Present address: Department of Internal Medicine, Catharina Ziekenhuis Eindhoven. ment of this response. ${ }^{12,13}$ In a previous study we demonstrated that the presence of antibodies in a population of dyspeptic patients could be correlated with the presence of helicobacter-associated gastritis. ${ }^{14}$ Therefore, it would appear that detection of antibodies to $H$. pylori could be used for epidemiological studies in larger population groups without the necessity of upper gastrointestinal endoscopy. This would enable the prevalence of antibodies in healthy individuals and acute or chronically ill patients who did not have dyspepsia, to be assessed, since at present there are only limited data available on healthy persons. ${ }^{15,16}$

In this paper we report the results of a serological study with an ELISA assay, performed to assess the prevalence of antibodies against $H$. pylori in healthy blood donors and non-dyspeptic patients in relation to age.

\section{Materials and methods}

\section{Sources of sera}

Blood (serum) samples were obtained from two groups of individuals: (1), 517 patients -233 men and 284 
women, mean age 56 (range 2-89) years, comprising a heterogenous group of in- and out-patients who were not referred because of dyspeptic complaints nor underwent endoscopy for follow-up of peptic ulcer disease or other reasons related to the upper abdominal tract; (2), 401 healthy blood donors- 362 men and 39 women, mean age 42 (range 19-65) years.

As a reference population, serum samples obtained from 64 patients ( 35 men, 29 women, mean age 64, range 17-85 years) referred for endoscopy because of dyspepsia were used. Of these, 48 patients were shown to have helicobacter-associated gastritis and 16 had normal antral mucosa on histological examination and $H$.pylori was not detected either microbiologically or histologically.

\section{Serological examination}

An enzyme-linked immunosorbent assay (ELISA), modified after the description of Kaldor et al., ${ }^{9}$ was used to measure specific IgG antibodies against $H$. pylori. Four strains of $H$. pylori (grown on blood agar with sheep blood $6 \%$, under microaerophilic conditions) were harvested and killed by heating at $60^{\circ} \mathrm{C}$. After sonication and preservation with sodium azide $0.1 \%$ a suspension was made and used as bacterial antigen. For pre-coating of flexible polyvinyl chloride microtitration plates (Titertek Immunoassay plate, Flow Laboratories The Netherlands), $100 \mu$ l of the suspension was diluted 1 in 50 with $60 \mathrm{mM}$ carbonate buffer (pH 9.6) with sodium azide $0.1 \%$. The coated plates were kept at $4{ }^{\circ} \mathrm{C}$ for $8-10 \mathrm{~h}$ and washed with phosphate-buffered saline with Tween 20 $0.5 \%$, pH 7.2 (PBS). After adding bovine serum albumin $1 \%$ in PBS and re-incubating for $2 \mathrm{~h}$, the plates were washed again with PBS. For controls buffer solution only was used. The prepared plates were kept in a humid environment at $4^{\circ} \mathrm{C}$.

For the test assay $50 \mu$ lof patient's serum diluted 1 in 10 in PBS was put into the wells of the test and control plates. After incubation for $90 \mathrm{mins}$ at $37^{\circ} \mathrm{C}$, the plates were washed with PBS and $50 \mu$ l of peroxidase labelled anti-human immunoglobulin (Peroxidase-conjugated rabbit immunoglobulin to human IgG, $\gamma$ chain; DAKO) was added. After incubation for a further $90 \mathrm{~min}$, the plates were washed and $50 \mu \mathrm{l}$ of a colour indicator $(\sigma$ phenylenediamine $20 \mathrm{mg}$ with $0.08 \mu \mathrm{l}$ of $\mathrm{H}_{2} \mathrm{O}_{2} 30 \%$ ) was added and the plates were incubated at room temperature in the dark. The colour reaction was stopped with $50 \mu \mathrm{l}$ of $4 \mathrm{M}$ sulphuric acid and the optical density (OD) was read at $492 \mathrm{~nm}$. Control sera and blanks were included in each assay. The measured OD values were normalised with respect to the control references to correct for minor day-to-day variations in the assay.

Cross-reactivity with Campylobacter jejuni was assessed by two different methods. Firstly, sera from 21 different patients with microbiologically proven $C$. jejuni infection were tested in the ELISA; mean OD was 0.66 (SD 0.40; only one sample produced an OD of 1.76), well below the cut-off points calculated for the presence of anti- $H$. pylori antibodies as shown below. Secondly, 20 of our positive sera were tested in a specific $C$. jejuni ELISA $^{17}$ (courtesy of W. C. van Dijk, Department of Microbiology, Stichting Samenwerkende Ziekenhuizen Delft, The Netherlands); none gave a positive reaction.

\section{Statistical analysis}

Statistical analysis was done with the $\chi^{2}$ test and the ttest. Sensitivity and specificity values were calculated with standard formula.

\section{Results}

\section{Assessment of the cut-off point}

For the assessment of the cut-off point in OD values to discriminate between presence or absence of anti-H. pylori antibodies, sera from patients of the reference population were used. Sera from the 48 patients with $H$.pylori infection diagnosed histologically or microbiologically, or both, gave a mean OD value of 3.63 (SD $1 \cdot 24$, range 1.06-6.45). The 16 helicobacter-negative patients gave a mean OD value of 0.70 (SD 0.45, range 0.21-1.99). After computing a receiver operating curve (ROC), the optimal values for sensitivity $(97.9 \%)$ and specificity $(94.4 \%)$ were found to be at OD 1.5 . Therefore, an OD value $>1.50$ was regarded as indicating the presence of antibodies against $\boldsymbol{H}$.pylori (i.e., a positive result) whereas an OD value $<1.50$ was interpreted as a negative result. Fig. 1 shows the OD values measured with the ELISA assay in these 64 reference patients.

\section{Antibodies in patients and healthy individuals}

The mean OD value for seropositive nondyspeptic patients was $2 \cdot 14$ (SD $0 \cdot 67$, range $1 \cdot 51$ $4 \cdot 13$ ), and for seropositive blood donors was $2 \cdot 32$ (SD $0 \cdot 47$, range $1 \cdot 51-3 \cdot 43$ ). There is no significant difference in OD between the two groups (fig. 2). However, there was a significant difference between the OD values of the seropositive reference population with proven helicobacter-associated gastritis and the seropositive blood donors and non-dyspeptic patients $(\mathrm{p}<0.0001)$.

Table I shows the total number of patients and blood donors with antibodies to $H$. pylori; $227(44 \%)$ of the 517 patients gave a positive antibody response, compared with $142(35 \%)$ of 401 normal blood donors $(\mathrm{p}<0.03)$. This difference remained significant after correction for age and sex.

\section{Antibodies in different age cohorts of non-dyspeptic patients and healthy blood donors}

In both groups, a parallel rise in the number of 


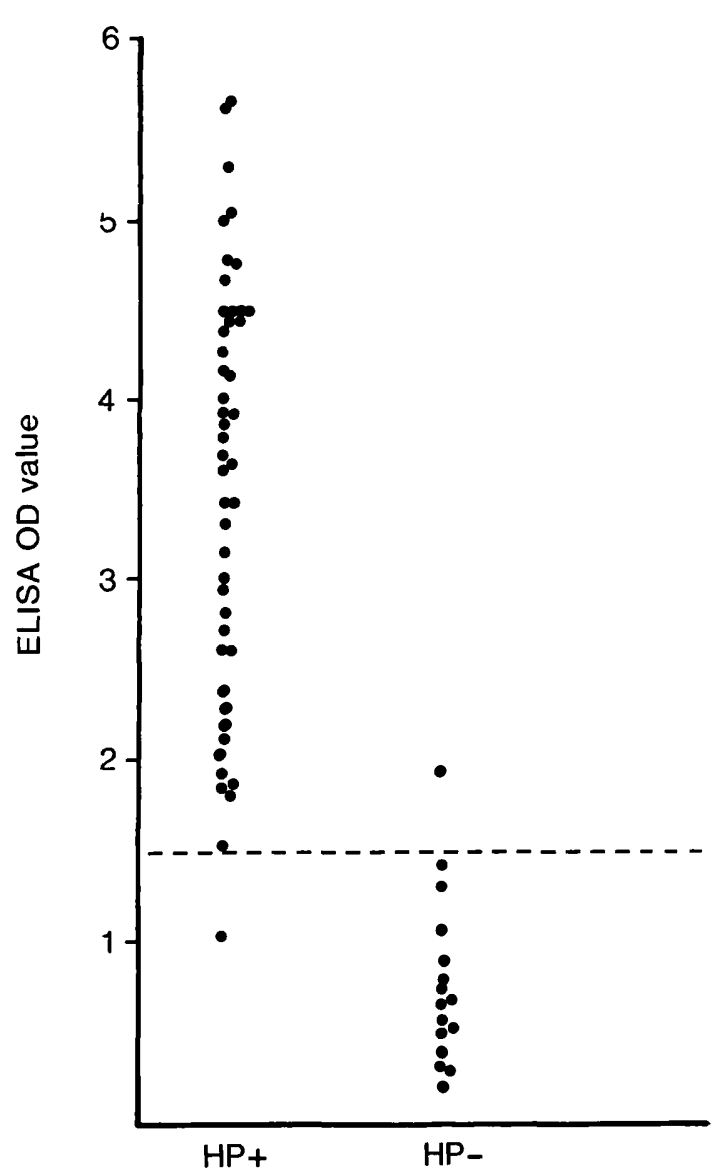

Fig. 1. OD values for sera of the reference population. $\mathrm{HP}+$, sera from patients with microbiological or histological evidence of $H$. pylori infection; HP - , patients with no such evidence. The dotted line indicates the cut-off point at OD 1.50 as calculated from the Receiver Operating Curve.

positive sera was found with increasing age. Table II shows the numbers of positive and negative sera in each age cohort.

\section{Discussion}

The presence of antibodies against $H$. pylori has been described previously in patients with histologically confirmed type B (antral) gastritis. ${ }^{16,18,19}$ Therefore, serological studies have been used to determine the prevalence of gastritis in larger population groups. ${ }^{15,20}$ However, whether detection of a systemic response to the micro-organism implies the presence of active helicobacter-associated gastritis remains questionable. Cross-reactivity with antibodies against other micro-organisms, notably $C$. jejuni, might affect the results of an assay used to detect anti- $H$. pylori antibodies. However, in a previous study we demonstrated that, in our

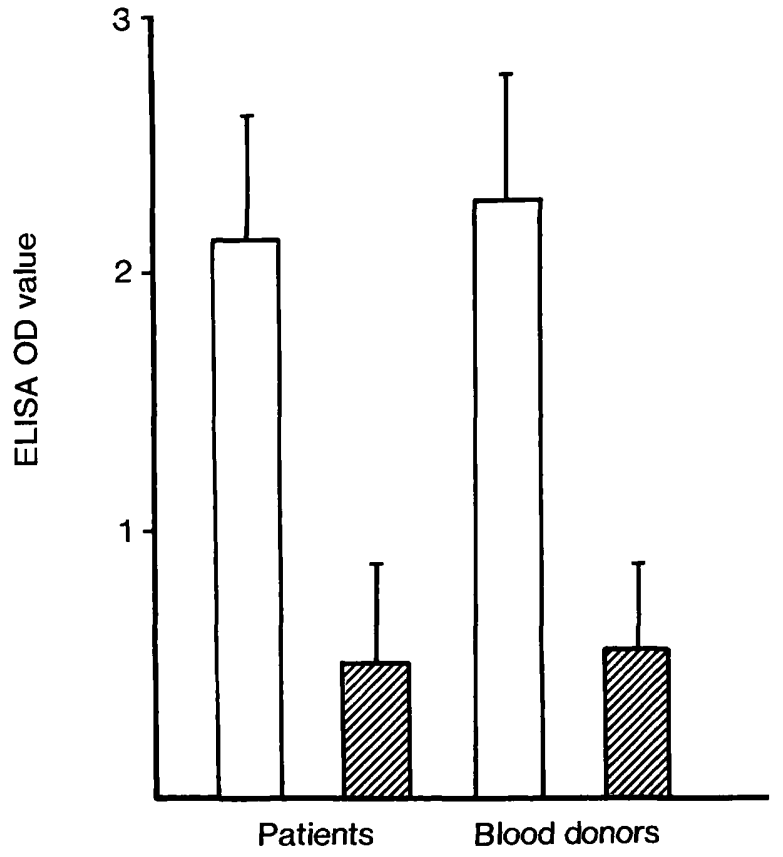

Fig. 2. Mean OD values and SD of sera from seropositive and seronegative non-dyspeptic patients and healthy blood donors; $\square$, positive sera; $\mathbb{Z}$, negative sera.

ELISA, there was no such interference with sera from patients with proven $C$. jejuni infection. ${ }^{15}$ Alternatively, anti- $H$. pylori antibodies could persist long after exposure to the micro-organism and remain detectable after the initially invoked gastritis has subsided. Other studies have shown decreasing IgG antibody titres after the successful treatment of helicobacter-associated gastritis. ${ }^{21,22}$

The results obtained with the reference population previously reported ${ }^{14}$ indicated that the presence of a systemic antibody response in dyspeptic patients was closely related to active helicobacterassociated gastritis. This is also evident from the high sensitivity and specificity values found after computing an ROC at OD 1.50 in the reference population in this study. These data suggest that the presence of antibodies may reflect active $H$. pylori infection. However, these conclusions cannot be extrapolated from our present results because the OD found in the reference population with helicobacter-associated gastritis is significantly higher than that found in the seropositive non-dyspeptic patients and normal blood donors. Since the antibody concentration decreases after eradication or suppression of $H$. pylori, our findings could indicate present or past infection in these individuals. To determine how many members of our two groups had active $H$. pylori infection would require microbiological and histological confirma- 
Table I. Occurrence of positive and negative sera in non-dyspeptic patients and normal blood donors

\begin{tabular}{lccc}
\hline & & Number of sera with OD values \\
\cline { 3 - 4 } \multicolumn{1}{c}{$\begin{array}{c}\text { Source of } \\
\text { sera }\end{array}$} & $\begin{array}{c}\text { Number } \\
\text { tested }\end{array}$ & $\begin{array}{c}\geqslant 1.5 \\
\text { (positive) }\end{array}$ & $\begin{array}{c}<1 \cdot 5 \\
\text { (negative) }\end{array}$ \\
\hline $\begin{array}{l}\text { Total } \\
\text { Non-dyspeptic patients }\end{array}$ & 517 & $227(44 \%)$ & $290(56 \%)$ \\
Blood donors & 401 & $142(35 \%)$ & $259(65 \%)$ \\
& & $\mathrm{p}<0.03$ & \\
$\begin{array}{l}\text { Age and sex adjusted } \\
\text { Non-dyspeptic patients }\end{array}$ & 381 & $162(43 \%)$ & $219(57 \%)$ \\
Blood donors & 401 & $142(35 \%)$ & $259(65 \%)$ \\
& & $\mathrm{p}<0.05$ & \\
\hline
\end{tabular}

tion of the presence of helicobacter-associated gastritis.

Our data show that antibodies against $H$.pylori can be detected more frequently in non-dyspeptic patients than in blood donors. Although both groups are not fully comparable, this finding remains after adjustment for age and sex, implying that the prevalence of active gastritis is or was higher in acutely or chronically ill patients. In an earlier study ${ }^{23}$ a high prevalence of non-ulcer dyspepsia and gastritis in patients admitted to hospital was observed. ${ }^{23}$ The explanation for this phenomenon can only be speculative. In a previous study we found $H$. pylori in a large number of antral biopsy specimens from dyspeptic patients with normal antral mucosa, although the micro-organisms were present in low numbers. ${ }^{24}$ Therefore we suggested that there is a balance between virulence of $H$.pylori and local mucosal defence

Table II. Occurrence of sera positive and negative for antibodies against $H$. pylori in consecutive age cohorts of non-dyspeptic patients and blood donors

\begin{tabular}{|c|c|c|c|c|}
\hline \multirow[b]{3}{*}{ Age cohort } & \multicolumn{4}{|c|}{ Number of sera from } \\
\hline & \multicolumn{2}{|c|}{ non-dyspeptic patients } & \multicolumn{2}{|c|}{ blood donors } \\
\hline & positive & negative & positive & negative \\
\hline $0-10$ & 1 & 5 & - & - \\
\hline $11-20$ & 2 & 10 & 0 & 5 \\
\hline $21-30$ & 18 & 39 & 10 & 43 \\
\hline $31-40$ & 13 & 37 & 35 & 92 \\
\hline $41-50$ & 27 & 37 & 54 & 82 \\
\hline $51-60$ & 43 & 46 & 36 & 32 \\
\hline $61-70$ & 61 & 62 & 7 & 5 \\
\hline $71-80$ & 46 & 36 & - & - \\
\hline $81-90$ & 16 & 18 & - & - \\
\hline
\end{tabular}

mechanisms, which when distorted would lead to gastritis. It is tempting to assume that in patients, who are generally in a suboptimal condition, this equilibrium is liable to be distorted, resulting in induction of gastritis.

In keeping with data from others ${ }^{11,25-27}$ we found an increase in occurrence of antibody with increasing age, in patients as well as in donors. The increasing prevalence of antibodies suggests that the micro-organism is acquired later in life, posing the question of how it is acquired. In a study of mentally retarded patients in an institution, ${ }^{15}$ the percentage of individuals with antibodies was significantly higher than in age-matched healthy controls, and correlated with the duration of stay in the institution. This suggests person to person transmission.

The most impressive observation from our study is that approximately one third of a randomly chosen population of blood donors appear to have significant levels of antibodies against $H$. pylori and thus an unknown number of these individuals will have active helicobacter-associated gastritis. The debate continues about the relationship between gastritis and dyspeptic complaints. ${ }^{6,28,29}$ Although our study design did not include data on dyspeptic complaints in the blood donors tested, it may be assumed that in general these "healthy" individuals did not suffer from dyspeptic complaints to a considerable extent. This raises the question of the clinical relevance of $H$. pylori infection. A definitive answer to this issue will require further studies evaluating evidence of $H$. pylori infection in relation to standard computerised questionnaires on dyspeptic complaints. Such a study is currently in progress.

We thank M. Wunderink (technical assistant) for performing the ELISA. 


\section{REFERENCES}

1. Marshall B J, Warren $\mathbf{J} \mathbf{R}$. Unidentified curved bacilli in the stomach of patients with gastritis and peptic ulceration. Lancet 1984; 1: 1311-1315.

2. Graham D Y, Klein P D. Campylobacter pyloridis gastritis: the past, the present and speculations about the future. Am J Gastroenterol 1987; 82: 283-286.

3. Price A B, Levi J, Dolby J M et al. Campylobacter pyloridis in peptic ulcer disease: microbiology, pathology and scanning electron microscopy. Gut 1985; 26: 11831188.

4. Axon A T R. Campylobacter pyloridis: what role in gastritis and peptic ulcer? Br Med J 1986; 293: 772-773.

5. Rathbone B J, Wyatt J I, Heatley R V. Campylobacter pyloridis, a new factor in peptic ulcer disease? Gut 1986; 27: 635-641.

6. Kreuning J, Bosman F T, Kuiper G, Wal A M, v.d. Lindeman J. Gastric and duodenal mucosa in healthy individuals. $J$ Clin Pathol $1978 ; 31$ : 69-77.

7. Siurala, M, Isokoscki M, Sipponen P. Gastritis. In : Demling L (ed) Klinische gastroenterologie, vol I. Stuttgart, Thieme. 1984: 321-337.

8. Perez-Perez G I, Dworkin B M, Chodos J E, Blaser M J. Campylobacter pylori antibodies in humans. Ann Int Med 1988; 109: 11-17.

9. Kaldor J, Tee W, McCarthy P, Watson J, Dwyer B. Immune response to Campylobacter pyloridis in patients with peptic ulceration. Lancet $1985 ; 1: 921$

10. Rathbone B J, Wyatt J L, Worsley B W et al. Systemic and local immune responses to gastric Campylobacter pyloridis in non-ulcer dyspepsia. Gut $1986 ; 27$ : 642-647.

11. Jones D M, Eldridge J, Fox A J, Sethi P, Whorwell P J. Antibody to the gastric campylobacter-like organism ("Campylobacter pyloridis") - clinical correlations and distribution in the normal population. J Med Microbiol $1986 ; 22: 57-62$.

12. Newell D G, Johnston B J, Ali M H, Reed P J. An enzymelinked immunosorbent assay for the serodiagnosis of Campylobacter pylori-associated gastritis. Scand J Gastroenterol 1988; 23 Suppl 142: 53-57.

13. Booth L, Holdstock G, McBride $\mathrm{H}$ et al. Clinical importance of campylobacter pyloridis and associated serum $\mathrm{IgG}$ and IgA antibody responses in patients undergoing upper gastrointestinal endoscopy. J Clin Pathol 1986; 39: 215-219.

14. Loffeld R J L F, Stobberingh E, van Spreeuwel J P, Arends J W. Diagnostic value of an immunoassay to detect anti-Campylobacter pylori antibodies in non-ulcer dyspepsia. Lancet 1989; 1 : 1182-1185.

15. Berkowicz J, Lee A. Person-to-person transmission of Campylobacter pylori. Lancet $1987 ; 2: 680-681$.
16. Wyatt J L, Rathbone B J, Heatley R V. Local immune response to gastric Campylobacter in non-ulcer dyspepsia. J Clin Pathol 1986; 39 : 863-870.

17. Herbrink $P$, van den Munckhof $H$ A $M$, Bumkens $M$, Lindeman J, van Dijk W C. Human serum antibody response in Campylobacter jejuni enteritis as measured with enzyme-linked immunosorbent assay. Eur J Clin Microbiol Infect Dis 1988; 7: 388-393.

18. von Wulffen $H$, Grote H J, Gatermann S, Loning T, Berger $\mathrm{B}$, Buhl C. Immunoblot analysis of immune response to Campylobacter pylori and its clinical associations. $J$ Clin Pathol $1988 ; 41$ : 653-659.

19. Jones D M, Lessells A M, Eldridge J. Campylobacter-like organisms on the gastric mucosa: culture, histological, and serological studies. J Clin Pathol 1984; 37: 10021006.

20. Dwyer B, Sun N X, Kaldor J et al. Antibody response to Campylobacter pylori in an ethnic group lacking peptic ulceration. Scand J Infect Dis 1988; 20: 63-68.

21. Rauws E A J, Langenberg W, Houthoff H J, Zanen H C, Tytgat G N J. Campylobacter pyloridis-associated chronic active antral gastritis: a prospective study of its prevalence and the effects of antibacterial and antinuclear treatment. Gastroenterology 1988; 94: 3340.

22. Vaira D, Holton J, Cairns S R et al. Antibody titres to Campylobacter pylori after treatment for gastritis. $\mathrm{Br}$ Med J 1988; $297: 397$.

23. Talley N J, McNeil D, Hayden A, Colreavy C, Piper D W. Prognosis of chronic unexplained dyspepsia : a prospective study of potential predictor variables in patients with endoscopically diagnosed non-ulcer dyspepsia. Gastroenterology 1987; 92: 1060-1066.

24. Loffeld R J L F, Potters H V P J, Arends J W, Stobberingh E, Flendrig J A, van Spreeuwel J P. Campylobacter associated gastritis in patients with non-ulcer dyspepsia. J Clin Pathol 1988; 41 : 85-88.

25. Marshall B J, McGechie D B, Francis G J, Utley P J. Pyloric campylobacter serology. Lancet 1984; $2: 281$.

26. Graham D Y, Klein P D, Opekun A R et al. Epidemiology of Campylobacter pyloridis infection. Gastroenterology 1987; $92: 1411$

27. Eldridge $\mathbf{J}$, Jones D M. Longitudinal study of the incidence of antibody to Campylobacter pylori in schoolchildren. In: Megrand F, Lamouliatte $\mathrm{H}$ (eds) Gastroduodenal pathology and Campylobacter pylori. Proceedings of the 1st Meeting of the European Campylobacter pyloristudy group. Amsterdam, Excerpta Medica, 1989.

28. Siurala M, Varis K V. Gastritis. In: Sircus W, Smith A N (eds) Scientific foundation of gastroenterology. London, Williams Heinemann, 1980: 357-369.

29. Joffe S N, Rao S S. Symptoms of gastritis. Scand J Gastroenterol 1982; 17 Suppl 79: 62-65. 